\title{
Sistem Pengunci Otomatis Terrarium Reptile Dengan Kendali Aplikasi Finger Print Berbasis Arduino
}

\author{
Eka Kusuma Pratama \\ Universitas Bina Sarana Informatika \\ email: eka.eem@bsi.ac.id
}

\begin{abstract}
ABSTRAK.Tingginya resiko kematian yang mengintai para penghobby reptile yang memiliki racun/bisa tinggi menyebabkan resah di kalangan masyarakat sekitar bahkan keluarga dekat, meskipun dari para penghobby sudah memiliki pengalaman yang lama dibidangnya bukan tidak mungkin bisa terjadinya hal fatal saat interaksi langsung dengan reptile yang berbisa tinggi. Walaupun seiring waktu keamanan pada kandang sudah ditingkatkan bukan tidak mungkin terjadi hal yang tidak diinginkan terjadi seperti hewan peliharaan tersebut terlepas dan bisa mengakibatkan resiko yang sangat berbahaya bagi sekitar.pembuatan sebuah terrarium dengan kunci otomatis berbasis mikrokontoler, yang dibuat terdiri dari beberapa komponen yaitu Arduino UNO, modul Bluetooth HC-05, Relay, Solenoid Lock dan smartphone android (termasuk fingerprint) sebagai pengontrol kunci otomatis yang saling terintegrasi menggunakan Arduino sebagai pengontrol alat yang digunakan. ini bermaksud untuk membantu mempermudah dalam mengunci pintu Terrarium dan sebagai keamanan ganda apabila ada tamu yang kurang memahami bahaya dari beberapa jenis reptile berbisa. Sistem rangkaian ini berfungsi untuk mengontrol penguncian pintu pada Terrarium dengan menggunakan smartphone.
\end{abstract}

Kata Kunci: Terrarium, Arduino, Finger Print

ABSTRACT.The high risk of death that lurks the fans reptile who have a poison/can be high cause a fret among the local community even close to the family, although from the hobby already has a long experience in their field is not impossible to happen fatal when direct interaction with the reptile high can. Although over time security in the cage has been increased, it is not impossible to happen unwanted things like the pet is detached and can cause a risk of danger to the surrounding. The creation of a terrarium with a Microcontroler-based auto-lock, which is made up of several components i.e. Arduino UNO, Bluetooth module HC-05, Relay, Solenoid Lock and Android smartphones (including fingerprints) as a fully integrated auto key controller using the Arduino as the tool controller used. This aims to help make it easier to lock the Terrarium door and as a double security when there are guests who are less familiar with the dangers of some types of reptile bercan. This circuit system serves to control door locking on Terrarium using a smartphone.

Keywords: Terrarium, Arduino, Finger Print

\section{PENDAHULUAN}

Tingginya resiko kematian yang mengintai para penghobby reptile yang memiliki racun/bisa tinggi menyebabkan resah di kalangan masyarakat sekitar bahkan keluarga dekat, meskipun dari para penghobby sudah memiliki pengalaman yang lama dibidangnya bukan tidak mungkin bisa terjadinya hal fatal saat interaksi langsung dengan reptile yang berbisa tinggi. Walaupun seiring waktu keamanan pada kandang sudah ditingkatkan bukan tidak mungkin terjadi hal yang tidak diinginkan terjadi seperti hewan peliharaan tersebut terlepas dan bisa mengakibatkan resiko yang sangat berbahaya bagi sekitar.

Perlunya keamanan ganda yang harus mampu menutup resiko (Ramadhan, Handoko, Informatika, Komputer, \& Nuswantoro, 2016) lepasnya reptile berbahaya dari kandang atau terrariumnya, seperti penambahan kunci finger print yang hanya bisa terbuka dengan ID yang sudah di daftarkan sehingga apabila ada orang asing yang ingin membuka kandang atau terrarium tidak akan bisa.

Prototype diawali dengan pembuatan sebuah terrarium dengan kunci otomatis(LIsah, Muhajirin, 2017) berbasis mikrokontoler, yang dibuat terdiri dari beberapa komponen yaitu Arduino UNO, modul Bluetooth HC-05, Relay, Solenoid Lock dan smartphone android (termasuk fingerprint) sebagai pengontrol kunci otomatis yang saling terintegrasi menggunakan Arduino sebagai pengontrol alat yang digunakan(Helmi Guntoro, Yoyo Somantri, 2013). ini bermaksud untuk membantu mempermudah dalam mengunci pintu Terrarium dan sebagai keamanan ganda apabila ada tamu yang kurang memahami bahaya dari beberapa jenis reptile berbisa. Sistem rangkaian ini berfungsi untuk mengontrol penguncian pintu pada Terrarium dengan menggunakan smartphone(Silvia, Haritman, \& Muladi, 2014).

Mekanisme cara kerja alat ini berfungsi dengan cara pertama kali pengguna harus menyimpan data sidik jari ke dalam ponsel smartphone android melalui sensor fingerprint atau sidik jari dengan cara 
menempelkan sidik jari ke sensor fingerprint yang ada pada smartphone android pengguna yang bisa diatur melalui pengaturan smartphone android pengguna masing-masing.

Oleh karena itu, di rancanglah "Sistem Pengunci Otomatis Terrarium Reptile Dengan Kendali

Aplikasi Finger Print Berbasis Arduino" sebagai keamanan tambahan pada terrarium dan sebagai kunci utama akses untuk membuka dan mengunci terrarium tersebut menggunakan Finger Print pemilik asli.

\section{METODE PENELITIAN}

Pengembangan project Hardware dan Software diawali dariseringnya pemberitaan jatuhnya korban jiwa pada reptiler yang memelihara reptile berbisa tinggi yang notabenenya belum ada penawar racun pada kebanyakan rumah sakit yang ada di Indonesia. beberapa kejadian tersebut dijadikan sebagai dasardimana terdapat rincian bahan serta materi yang dibuat secara sistematis dan logis sehingga dapat dijadikan pedoman dalam membantu menyelesaikan masalah yang ada dan diharap mampu mengurangi jumlah korban dari kegemaran memelihara reptile berbisa tersebut.

\subsection{Konsep Fungsioal Sistem}

Rancangan ini adalah sistem rangkaian untuk membuka dan mengunci pintu yang menggunakan papan mikrokontroler Arduino Uno yang didalamnya terdapat Atmega328p sebagai pusat pemrosesan data(Fatoni, Rendra, Studi, Komputer, \& Pendahuluan, 2014), Bluetooth sebagai pemberi sinyal perintah kepada Arduino, yang di kirim dari smartphone dan sensor fingerprint pada smartphone sebagai komponen utama dalam mengakses kunci pintu(Saefullah, Immaniar, \& Juliansah, 2015).

Untuk memaksimalkan alat pada sebuah pintu, aktifkan rangkaian dengan cara memberikan tegangan 9 Volt atau 12 Volt pada Arduino dari adaptor power supply. Kemudian Jika alat pada rangkaian Arduino menyala maka alat siap bekerja, namun jika rangkaian Arduino belum memyala maka periksa kembali tenaga pada daya tersebut.

Sistem kerja alat ini pertama rangkaian disambungkan dengan adaptor power supply 9 Volt atau 12 Volt, kemudian Bluetooth smartphone di hubungkan terlebih dahulu dengan Bluetooth HC-05. Bluetooth HC-05 di sambungkan pada Arduino UNO dimana pin TX di sambungkan pada pin RX untuk mengirim data serial dan pin RX di sambungkan pada pin TX untuk menerima data serial, pin VCC pada bluetooth HC-05 terhubung ke pin $3.3 \mathrm{~V}$ pada Arduino gunanya sebagai aliran listrik, dan pin GND ke pin GND Arduino sebagai arus negative, lalu Arduino UNO menerjemahkan kedalam bentuk perintah gerakan pada solenoid dimana kabel hitam dihubungkan ke power jack arduino dan kabel merah dihubungkan ke port COM relay sebagai pengatur arus ke solenoid, sebelum arus terkirim ke solenoid arus akan melalui relay terlebih dahulu, didalamrelay arus akan dikontrol. Diman pin IN atau signal pada relay di hubungkan ke pin 13 pada arduino, pin GND di relay dihubungkan ke pin GND pada arduino sebagai arus negative dan pin VCC pada relay terhubung ke pin $5 \mathrm{~V}$ pada arduino sebagai aliran listrik. 


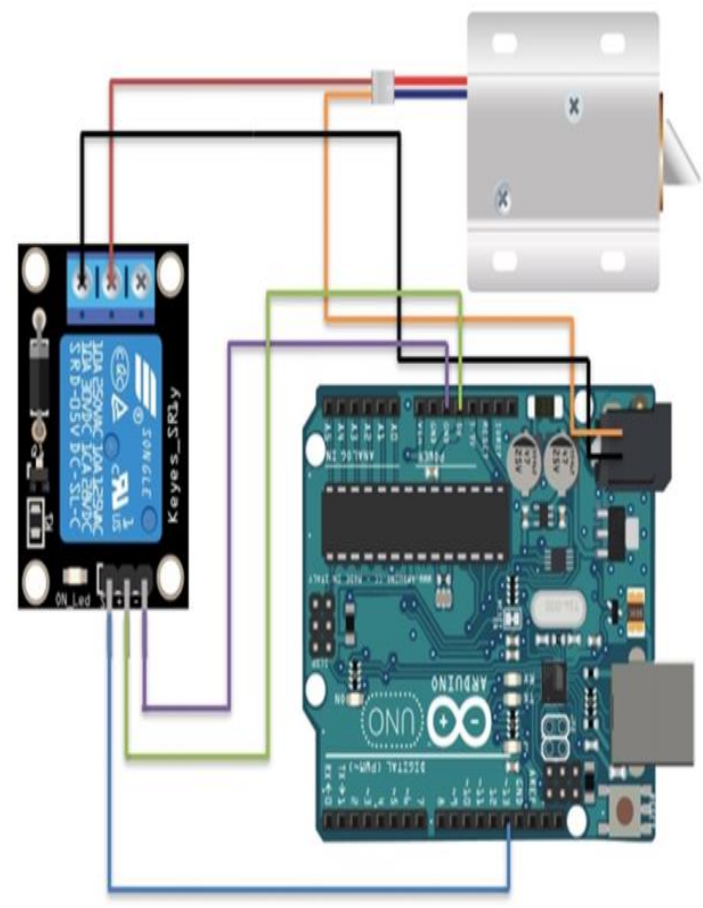

Gambar 1. Desain Wiring Prototype

Sensor fingerprint android bekerja dengan mendeteksi kecocokan sidik jari pengguna dengan data sidik jari yang sebelumnya pengguna simpan dan ketika mendeteksi adanya kecocokan sidik jari maka aplikasi akan memberikan perintah untuk membuka kunci pintu kepada mikrokontroler arduino begitu juga sebaliknya, apabila terdeteksi ketidak cocokkan sidik jari maka pintu akan terkunci.

\subsection{Perancangan Perangkat Lunak}

Untuk dapat berjalan sesuai dengan fungsinya, alat ini membutuhkan suatu program. Program yang dimaksud adalah sebuah perangkat luak dimana sintaks dan perintah-perintah di susun dalam sebuah software khusus yang bernama Arduino IDE untuk kemudian di masukan kedalam kontroler yang terdapat pada Arduino uno. Software Arduino IDE menggunakan bahasa $\mathrm{C}$ dan penggunaannya cukup mudah dan sangat membantu untuk pembuatan program ini. 


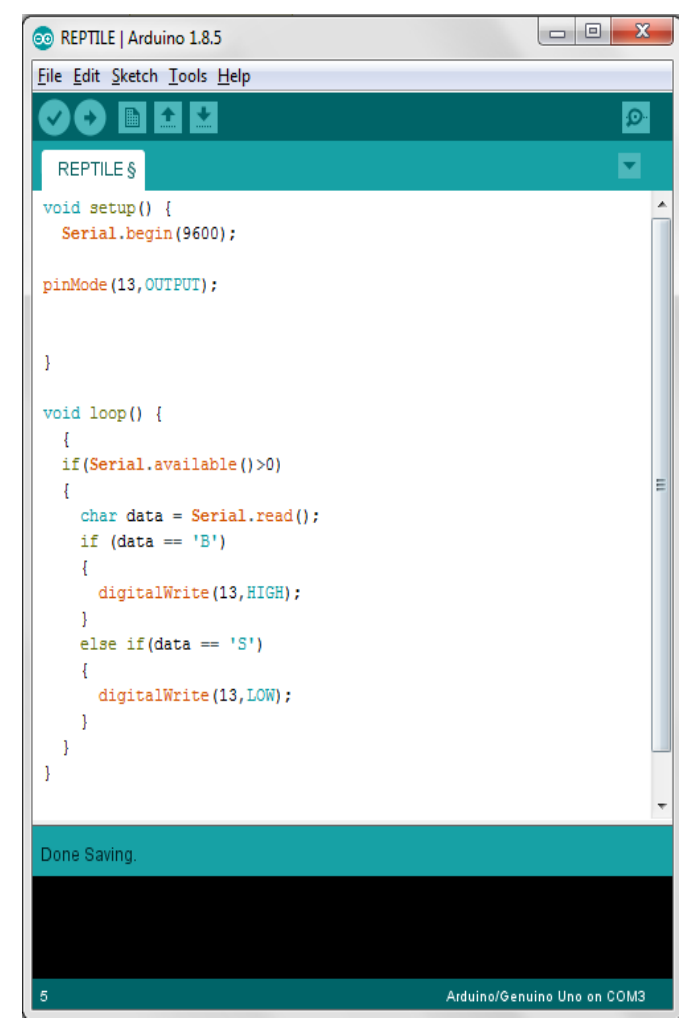

Gambar 2. Proses Coding Program
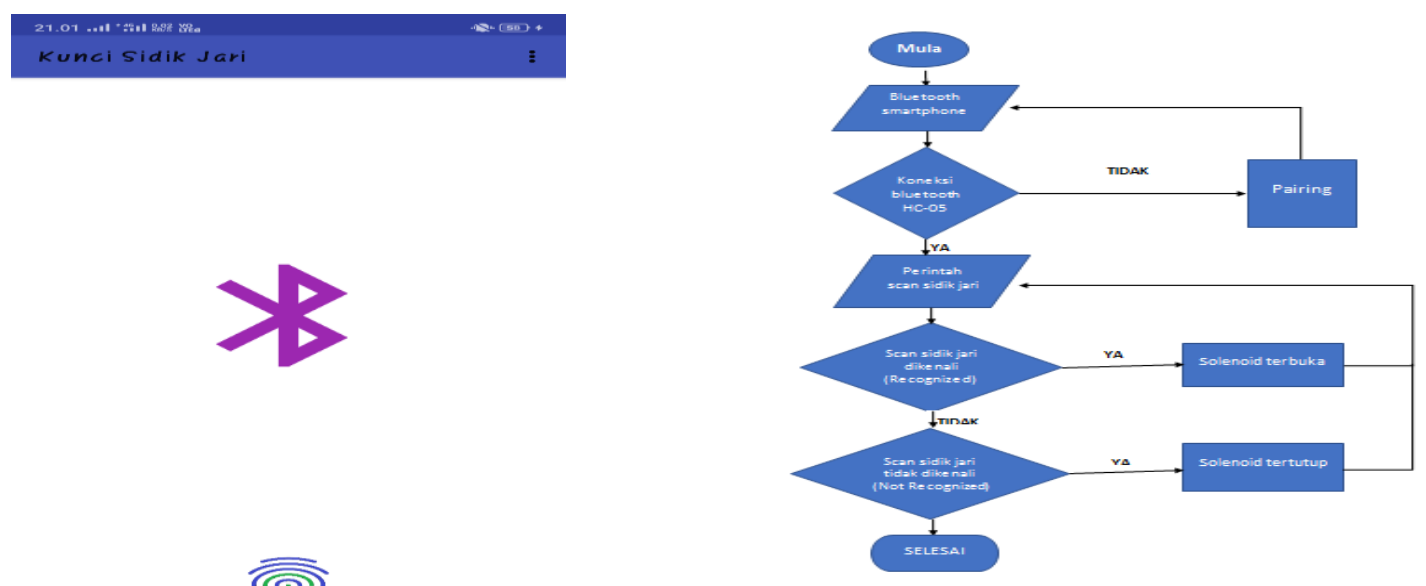

Gambar 3. Interface antar muka Android

Gambar 4. Flowchart sistem

Pembuatan Aplikasi menggunakan kodular untuk membuat tampilan aplikasi yang dapat dibentuk sesuai dengan keinginan kita. Dalam hal ini pembuatan rancangan tampilan aplikasi seperti yang bisa dilihat pada Gambar 3, Perintah untuk terhubung Bluetooth HC-05 dan memberi informasi jika sudah terhubung, jika Bluetooth dari alat sudah terhubung aplikasi maka aplikasi dapat menjalankan perintah button open atau close.

\section{PEMBAHASAN}

Dalam percobaan yang penulis lakukan pada alat ini, dan didapatkan hasil yang sesuai dengan apa yang diharapkan. Semua komponen dapat bekerja dengan baik dan sesuai dengan fungsinya. Hasil percobaan yang penulis lakukan melingkupi input, proses dan output. Adapun hasil percobaan diantaranya sebagai berikut: 
Percobaan ini berfungsi untuk mengetahui apakah rangkaian dapat bekerja dengan baik, maka dari itu penulis akan menampilkan data dari hasil percobaan alat yang telah dilakukan. Percobaan ini dilakukan dengan cara mengukur jarak jangkauan yang mampu dicapai oleh bluetooth untuk dapat berhubungan dan mampu membawa perintah dari smartphone ke mikrokontroler. Pada saat yang bersamaan pengukuran waktu eksekusi dilakukan dengan menggunakan stopwatch. Pengujian ini ini dibagi menjadi dua bagian, yaitu dapat dilihat pada Tabel 1 dan Tabel 2.

Tabel 1.Uji Kalibrasi Perintah menggunakan Smartphone(indoor)

\begin{tabular}{|c|c|c|}
\hline Jarak & Hasil & Waktu Eksekusi (detik) \\
\hline 1 meter & lancar menerima perintah & 1 \\
\hline 2 meter & lancar menerima perintah & 1 \\
\hline 3 meter & lancar menerima perintah & 1 \\
\hline 4 meter & lancar menerima perintah & 1 \\
\hline 5 meter & lancar menerima perintah & 3 \\
\hline 6 meter & lancar menerima perintah & - \\
\hline 7 meter & lancar menerima perintah & 1 \\
\hline 8 meter & lancar menerima perintah & 1 \\
\hline 9 meter & koneksi terputus & 1 \\
\hline
\end{tabular}

Tabel 2.Uji Kalibrasi Perintah menggunakan Smartphone(outdoor)

\begin{tabular}{|c|c|c|}
\hline Jarak & Hasil & Waktu Eksekusi (detik) \\
\hline 1 meter & lancar menerima perintah & 1 \\
\hline 2 meter & lancar menerima perintah & 1 \\
\hline 3 meter & lancar menerima perintah & 1 \\
\hline 4 meter & lancar menerima perintah & 3 \\
\hline 5 meter & lancar menerima perintah & - \\
\hline 6 meter & lancar menerima perintah & 1 \\
\hline 7 meter & koneksi terputus & \multicolumn{2}{|c|}{} \\
\hline
\end{tabular}

\subsection{Pengujian pada Apikasi Android}

Pengujian terhadap aplikasi android dimaksudkan untuk mengetahui apakah aplikasi yang digunakan untuk menggerakkan kunci pintu dapat bekerja dengan baik atau tidak. Pengujian ini dilakukan sebagai berikut:

Aktifkan bluetooth android secara manual setelah itu pairing bluetooth android dengan bluetooth HC-05 dan masukkan password "1234", lalu buka aplikasi yang akan digunakan. Setelah aplikasi dibuka, klik icon bluetooth maka akan muncul list bluetooth yang tersimpan di android. Lalu pilih nama bluetooth HC-05 dan pastikan terhubung, contoh gambar 5 .

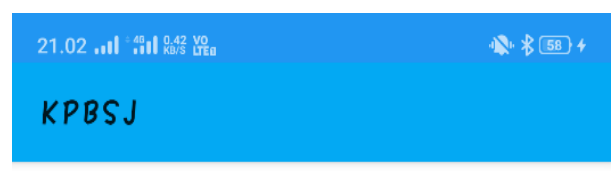

D8:50:E2:C3:EO:FC NONAME-PC

98:03:32:F5:A0:76 HCO5

30:23:84:BE:06:54 TH-SIOU

$40: 2 C: F 4: 52: 49: A B P C$

Gambar 5. Test Koneksi Bluetooth 
Hasil pengujian di atas menunjukkan bahwa kunci pintu yang dilakukan oleh solenoid dengan relay sebagai pengatur arus on dan off dapat bekerja dengan baik terhadap perintah yang dikirimkan oleh smartphone melalui bluetooth setelah pengguna menscan sidik jarinya dan diteruskan oleh arduino.

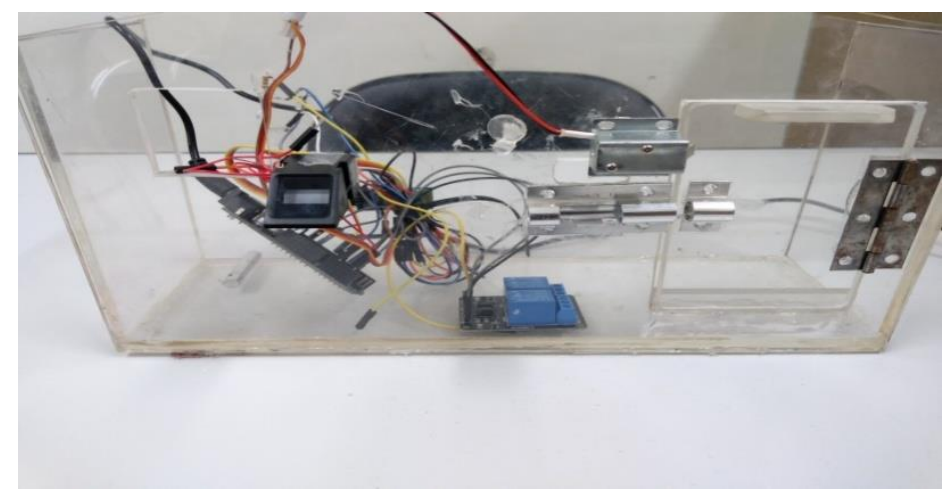

Gambar 6. Perangkat IDE

\section{KESIMPULAN}

Dari hasil pembahasan perancangan sistem dapat dibuat kesimpulan, yaitu:

1. Sistem dapat terkoneksi dengan handphone menggunakan koneksi bluetooth dengan jarak maksimal 8 meter diluar ruangan dan 6 meter diluar ruangan.

2. Terrarium tidak akan terbuka tanpa Finger Print yang tepat.

3. Terrarium akan terkunci otomatis saat ditinggalkan.

4. Tanpa aplikasi yang sesuai dan finger print pemilik terrarium tidak akan terbuka, yang menjadikannya sangat aman.

5. Aplikasi dapat terinstal dengan baik diversi terbaru bahkan di versi lollipop.

Saran untuk pengembangan bisa ditambahkan notifikasi apabila ada yang mencoba membuka paksa terrarium saat terkunci.

\section{DAFTAR PUSTAKA}

Anwar, Y. El, Soedjarwanto, N., Repelianto, A. S., Belakang, A. L., \& Jari, A. S. S. (2000). Prototype Penggerak Pintu Pagar Otomatis Berbasis Arduino Uno ATMEGA 328P dengan Sensor Sidik Jari.

Fatoni, A., Rendra, D. B., Studi, P., Komputer, S., \& Pendahuluan, I. (2014). PERANCANGAN PROTOTYPE SISTEM KENDALI LAMPU MENGGUNAKAN HANDPHONE ANDROID, 1 (September).

Helmi Guntoro, Yoyo Somantri, E. H. (2013). RANCANG BANGUN MAGNETIC DOOR LOCK MENGGUNAKAN KEYPAD DAN SOLENOID BERBASIS MIKROKONTROLER ARDUINO UNO, 12(1), 39-48.

LIsah, Muhajirin, iskandar akbar. (2017). Sistem keamanan pintu berbasis arduino mega. Jurnal Informatika UPGRIS, 3(2), 99-104.

Ramadhan, A. S., Handoko, L. B., Informatika, T., Komputer, F. I., \& Nuswantoro, U. D. (2016). RANCANG BANGUN SISTEM KEAMANAN RUMAH BERBASIS ARDUINO MEGA 2560. Techno.Com, 15(2), 117-124.

Saefullah, A., Immaniar, D., \& Juliansah, R. A. (2015). SISTEM KONTROL ROBOT PEMINDAH BARANG MENGGUNAKAN.

Silvia, A. F., Haritman, E., \& Muladi, Y. (2014). RANCANG BANGUN AKSES KONTROL PINTU GERBANG BERBASIS ARDUINO DAN ANDROID, 13(1), 1-10. 